This is an author's manuscript of an article accepted for publication in the Journal of Mathematics and the Arts, published by Taylor \& Francis. Please cite it as

Araújo, A. B. (2020). Explorations in Rational Drawing. Journal of Mathematics and the Arts, 14(1-2), 4-7.

https://doi.org/10.1080/17513472.2020.1734437

\title{
Explorations in Rational Drawing
}

\author{
António Bandeira Araújo ${ }^{1}$
}

${ }^{1}$ CIAC-UAb, Univ. Aberta, Portugal. antonio.araujo@uab.pt

Abstract: We discuss the position of the author's spherical perspective work within a tradition of Rational Drawing, a discipline at the interface of mathematics and the arts.

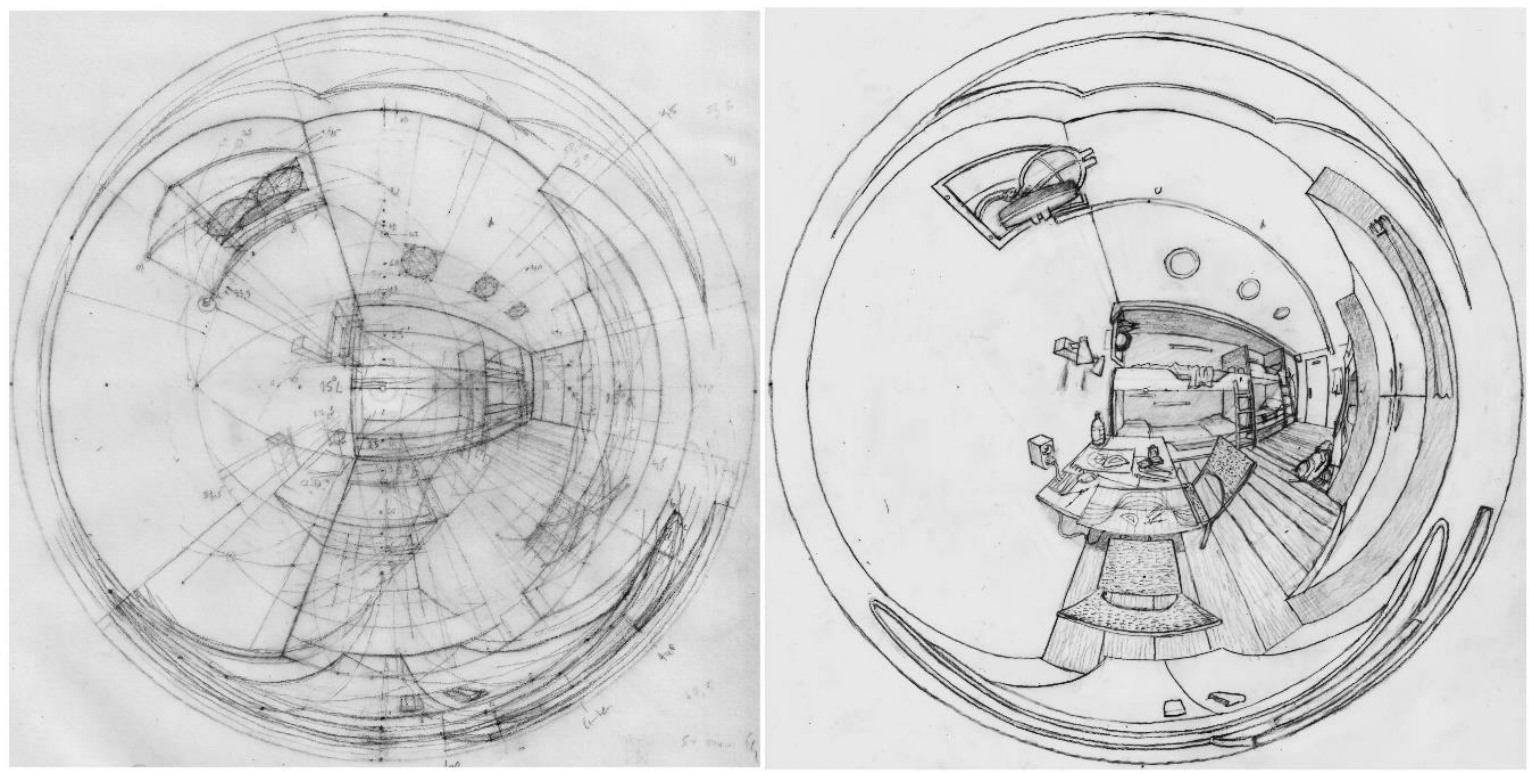

Figure 1. Spherical perspective drawing of a room on a ship. Graphite on a tracing paper. $30 \times 30$ [cm].

Note to the reader:

In 2020, the J. Math.Arts published a special number containing only "artist's statements" of people working at the interface between art and mathematics. The article should be a short statement, include no abstract, and explain the work of the artist/mathematician by reference to the work displayed in the article's figures. I included a short abstract in this Author's Manuscript, which is absent from the published version.

This work was done while the author was supported by funds from Fundação para a Ciência e a Tecnologia (FCT) project UID/Multi/04019/2013. 


\section{Explorations in Rational Drawing}

Drawing has many faces. One finds in it what one seeks. Most of my early drawing instructors focused exclusively on so-called right-brain methods, meaning roughly non-symbolic and nonanalytic, in some pop-neurological sense. I found myself lamenting: half a brain is such a terrible thing to waste! There is also a place for Rational Drawing.

Drawing, like mathematical modeling, filters a reality too complex to be seen in the raw. A simplistic slogan goes: "just draw what you see". But the innocent eye sees only chaos. Both drawing and mathematics are suppressive devices: they model, select and abstract, they exclude mercilessly so that something at all may be glimpsed.

If art is exploration, then there is a need for cartographers to settle the confused impressions of the explorer into clear maps so that further forays can be launched into the unknown. There is no push without firm ground under the feet - only flailing. Rational Drawing establishes footholds for art.

I frame my work within a tradition I call Rational Drawing, where I would include Brunelleschi and Monge, but also Taylor and Euclid. I see drawing as a tool for thinking about the world and our visual perception of it. I see Brunelleschi's famous experiment at the doors of Florence's cathedral [1] not merely as the start of perspective but as the seminal experiment in psychophysics, studying the relationship between physical stimuli and visual sensation, through the creation of measurable, artificial, mimetic objects. I see Euclid anticipating this with his Optics [2], and Taylor clarifying it with his Linear Perspective [3]; theory both cradling and crowning experiment, with centuries in between. And, in between cradle and crown, I see an ascent through artistic creation and problem solving by the laborious hand and eye of working artists, illustrators, illusionists, theoreticians: Alberti, Piero de La Francesca, Dürer, Leonardo, Niceron, Pozzo, and all that host that put no barriers between art and mathematics, but saw mathematics as a tool of the trade, as legitimate as the brush.

My process runs on that same feedback loop between mathematics and drawing practice. I throw mathematics and art into a box and watch them feed upon each other. In drawing one knows that rules are to be broken. In Rational Drawing one further knows that rules are to be broken so that new rules may be found. Repeat.

It was through drawing practice that I found my first research problem at the interface of art and mathematics. I was a draughtsman before I was a mathematician, and during my academic training in physics and mathematics I took classes in painting and scientific illustration. I did illustration work but mostly kept drawing alive by voraciously recording the people and places of my commute, doing what is now called urban sketching.

Often I found myself wanting to draw large-angle views. In the literature I found Barre and Flocon's treatment of the azimuthal equidistant (fisheye) spherical perspective [4]. It was a proper perspective - i.e., a systematic ruler and compass construction of all vanishing points - but spherical was a misnomer: it only rendered a hemisphere. As a mathematician, I was unsatisfied with transitioning from a linear perspective, where a line may have one or no vanishing points, to 
a (hemi)spherical perspective where it has two or one. Beauty demanded symmetry: a line should have exactly two vanishing points, obtainable by clear ruler and compass methods.

In 2015 I published, as an arXiv preprint, the generalization of Barre and Flocon's method to the full sphere. Now I could do 360-degree perspectives such as the one in Figure 1, using ruler and compass constructions. Only then I did a proper investigation of the literature for this problem I had deliberately solved in isolation, as a joyful complement to my main research. I found to my surprise that for the most part, my method was indeed new. Earlier attempts had been qualitative or grid-based, but not a full solution in the sense of Barre and Flocon. Apart from these, the world seemed to have moved on to computer algorithms. As fashion changes, problems are often discarded rather than solved.

Slowly, what started as an isolated, amusing work on the side became my main research. I couldn't shake the impression that Barre and Flocon had been hindered by a philosophical misconception regarding the nature of perspective, connected to the long-standing conventionalist versus realist debate. I proposed that the definition of perspective should have anamorphosis at its core, itself redefined with an emphasis on topological compactification. This could solve many philosophical misconceptions [5]. Because there is nothing more practical than good philosophy, this not only settled my more ethereal concerns but suggested a schema to solve general spherical perspectives. By the time my fisheye preprint became a paper in the Journal of Mathematics and the Arts [6], I had solved a second spherical perspective: the equirectangular case [7].

Equirectangular format is the standard for 360-degree cameras. Hence an equirectangular drawing (Figure 2) can be automatically rendered as a virtual reality (VR) panorama. This is a technological update of the old tradition of anamorphic illusionary drawing. This connection between handmade drawing and digital visualization led me to new paths, both artistically and mathematically. I started thinking in terms of a hybrid medium, where both the drawing on paper, the anamorphic drawing on the sphere and the immersive visualization are interconnected objects of simultaneous aesthetical consideration. Many of my observational drawings take the character of mathematical explorations under the guise of urban sketches. In Figure 2, the perspectival scaffolding is left visible, because the scaffolding is the message. The whole drawing - an urban sketch on location is an exploration of perspective multiplication [8]: all arches are built from the central one using the two vanishing points of the diagonal across it. Many of my drawings have this dual nature: observational drawing and the manifestation of a perspective principle.

This interaction between virtual reality and handmade drawing led me to teach many workshops to architects, artists and mathematicians worldwide, as VR panoramas are motivating a veritable renaissance of perspective drawing. I now teach a Ph.D. course to students of digital media art at Aberta University (Portugal), using drawing to explore the mathematics, physics, and programming of various visualization algorithms, focusing on permanent principles like anamorphosis instead of accidental software features that keep changing every day. Such a focus on essentials is necessary to balance a technological trend towards a black box mentality. Rational Drawing can help expose the innards of these black boxes, reminding us that the most important place to integrate new "software" is in our own heads. It is my goal to create art and mathematics that lead to technological developments that reinvigorate rather than replace the fundamental mode of thought that we call drawing. 


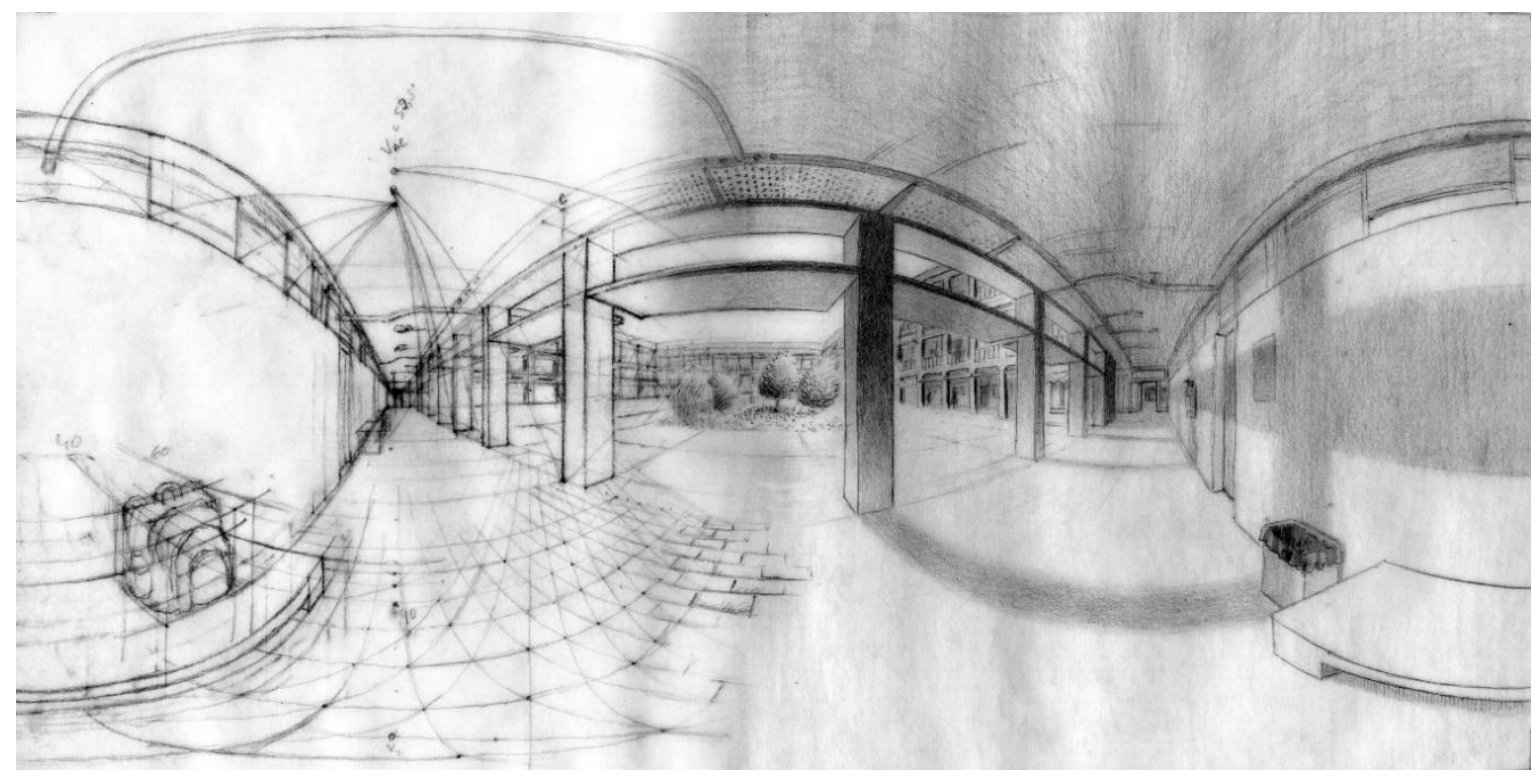

Figure 2. Equirectangular drawing of a corridor. Graphite on tracing paper. $28 \times 14[\mathrm{~cm}]$. See author's website [5] for VR visualization.

\section{References:}

[1] A. B. Araújo, Drawing Equirectangular VR Panoramas with Ruler, Compass, and Protractor, Journal Of Science And Technology Of The Arts, vol. 10, no 1 (2018), pp. 15-27. https://doi.org/10.7559/citarj.v10i1.471

[2] A. B. Araújo, Topologia, Anamorfoses, e o bestiário das Perspectivas curvilíneas, Convocarte, no. 2 (2016), pp. 51-69.

[3] A. B. Araújo, Ruler, compass, and nail: constructing a total spherical perspective, Journal of Mathematics and the Arts, vol. 12, no 2-3 (2018), pp. 144-169. https://doi.org/10.1080/17513472.2018.1469378

[4] A. Barre and A. Flocon, La perspective Curviligne. Flammarion, Paris, 1964.

[5] A. B. Araújo, Author's Website, http://www.univ-ab.pt/ aaraujo/full360.html.

[6] A. B. Araújo, Eq A Sketch 360, a Serious Toy for Drawing Equirectangular Spherical Perspectives, in Proceedings of Artech 2019, 9th International Conference on Digital and Interactive Arts (Artech 2019), ACM, Braga, 2019, 8 pages. https://doi.org/10.1145/3359852.3359893

[7] K. Andersen, The geometry of an art: the history of the mathematical theory of perspective from Alberti to Monge. Springer Science \& Business Media, 2008.

[8] H. E. Burton, Euclid's Optics, Journal of the Optical Society, vol. 35, № 5 (1945), p. 357-72.

[9] K. Andersen, Brook Taylor's Role in the History of Linear Perspective. Springer, 1992. 